\title{
Extraction and Characterization of Mucuna Seeds Oil
}

\author{
Omofuma, F.E ${ }^{*}$, Sholola, S.O.A ${ }^{1}$ \\ *Department of Chemical Petroleum Engineering, Igbinedion University Okada, Edo State, Nigeria \\ ${ }^{1}$ Department of Chemical Sciences, Igbinedion University Okada, Edo State, Nigeria
}

\begin{abstract}
The economic exigencies of the moment dictate that the material to be compounded do not only meet end service requirement but practically cheap enough to stand market competition. Hence this research will attempt to introduce an innovation aided at bringing the cost of production of Polymer products to the affordable level by introduction of "Mucuna seeds oil" as process aids to facilitate processing, and improve the mechanical and strength properties of the rubber during milling, mixing, calendaring and extrusion by providing lubrication for the rubber molecules; to aid in the dispersion of fillers resulting in the improvements of strength properties and abrasion resistance, and to extend the rubber by giving it larger volume. Relevant test like proximate analysis of the seeds as well as the physiochemical properties of the oil was carried out.
\end{abstract}

Keyword: Lubrication, Mucuna, Processing Aids, Polymers, Rubber

\section{INTRODUCTION}

Process aids (process auxiliaries) are important additives without which some synthetic polymers would be difficult to process and certain shaping processes would be impossible to carry out. They are needed only in relatively small amounts. They are used with most thermoplastic synthetic polymers and thermoset polymers (curable moulding compositions), and have a decisive role in raising the output performance of production machinery, improving the quality of finished products, and permitting the use of new processing technologies.

Although a wide variety of processing aids are known, problems continue to arise in the use of these substances in synthetic polymer compositions, e.g., it is known that some processing aids migrate at room temperature to the surface of finished components and thus impair their appearance, or lead to the release of undesired residue (emissions) due to their volatility. For instance, stearic acid can deposit on the surface of plasticized PVC as an undesirable white deposit (blooming).

The type of oils used as process aids and extenders are classified under the heading: paraffinic, naphthenic and aromatic, according to the value of the viscosity gravity constant (VGC).

$$
\mathrm{VGC}=\frac{\mathrm{G}-0.24-0.022 \log _{10}\left(\mathrm{~V}_{2}-35.5\right)}{0.755}
$$

Where $\mathrm{G}=$ specific gravity at $15.5^{\circ} \mathrm{C}$, and $\mathrm{V}_{2}-$ Saybolt viscosity at $99^{\circ} \mathrm{C}$.

Oils with VGC around 0.8 are classified as paraffinic, and those with 1.0 as extreme aromatic (Horn, 1968)

\subsection{Effects of Process Aids on Vulcanizates Properties of Polymer}

As a generalization, aromatic oils give best processability, but likely to have detrimental effects on staining, colour stability and ageing resistance. Paraffinic oils are usually less effective as process aids, but have little effect on ageing performance, contact staining or colour stability. Performance at low temperature is also better than that of aromatic oil; naphthenic oils fall between aromatic and paraffinic typed in their effect on performance of rubber. Chlorinated paraffinic hydrocarbon is sometimes used as flame retardants plasticizer, e.g., cereclor (ICI) (Horn, 1968)

\subsection{Application of Processing Aids}

In contrast to peptizers, petroleum oils and petroleum jelly function in a physical rather in a chemical manner; their effect is not dependent on the temperature of mixing. From 5 to $10 \mathrm{phr}$ acts as a 
plasticizer during processing causing a reduction in viscosity and easing filler incorporation. Petroleum oils are also used as extenders to reduce the cost of rubbers compounds, they may be incorporated during the manufacture of certain synthetic polymers e.g., oil extended SBR and EPDM or may be added during compounding with substantial quantities of fillers, to offset the softening on the vulcanizates (Horn, 1968).

\section{MATERIALS AND MeTHODS}

\subsection{Sample Collection and Preparation}

Mucuna beans were sourced from bushes round the geo-metropolis of Egor Local Government Area of Edo State, Nigeria. The Mucuna was placed on a heating pan for slight heating in an oven so as to ease the removal of the bean from the shaft; thereafter, drying of the seeds was done under the heat of the sun for several days until the seeds were dried enough for grinding. 1000g of seeds (Mucuna mucunoide) was weighed after drying and grinded into powder using an industrial grinder

\subsection{Proximate Composition of Seeds}

\subsubsection{Extraction Process}

$30 \mathrm{~g}$ of sample was weighed and placed in the thimble of the soxhlet extractor and allowed to extract for $2 \mathrm{hrs}$ using $\mathrm{n}$-hexane as solvent

Lipid content; weight of sample before extraction - weight of sample after extraction $\quad * 100$

initial weight of sample

\subsubsection{Determination of \% Moisture Contents}

$2 \mathrm{~g}$ of seeds was weighed into a crucible and placed in the hot air oven at $80^{\circ} \mathrm{C}$. After cooling of the sample in a desiccator, intermittent weight determination was done until constant weight was observed.

Moisture content $\%=$ original weight of sample - final weight of sample $* 100$

Original weight of sample

\subsubsection{Determination of $\%$ Ash Content}

$2 \mathrm{~g}$ of the seeds was weighed into a crucible and placed in a heating furnace and ashed for $4 \mathrm{hrs}$. The ashing period was then terminated by the absence of smoke from the crucible.

$$
\text { Ash content } \%=\frac{\text { final weight }}{\text { initial weight }} * 100
$$

\subsection{Physiochemical Composition of Oil}

\subsubsection{Purification of Oil Sample}

After extraction using n-hexane as solvent, the solvent was then evaporated under heat at $60^{\circ} \mathrm{C}$ using heating mantle. The recovered oil was further purified in the separating funnel by adding oil sample to chloroform/methanol/ $/ 0.3 \% \mathrm{NaCl}$ solution at a ratio of $(3: 2: 1)$. The Chloroform layer was then repurified using chloroform $/ 0.5 \% \mathrm{NaCl}$ at the ratio $(2: 1)$. The lower layer (chloroform layer) was decanted and the chloroform was then evaporated using heat at $40^{\circ} \mathrm{C}$.

\subsubsection{Determination of Acid Value}

$1 \mathrm{ml}$ of oil sample was measured into a $250 \mathrm{ml}$ conical flask and $5 \mathrm{ml}$ of chloroform and $0.1 \mathrm{ml}$ of phenolphthalein was added respectively; the solution was then titrated against $0.1 \mathrm{M} \mathrm{KOH}$. The end point was reached until pink colouration became persistent. The tire value was then recorded.

$$
\text { Acid value }=\frac{56.1 * 0.1 \mathrm{M} * \text { titre value }}{\text { weight of oil }}
$$

Where $56.1=$ mass of $\mathrm{KOH}$

\subsubsection{Determination of Saponification Value}

$1 \mathrm{ml}$ of oil sample was measured into a $250 \mathrm{ml}$ conical flask and dissolved into $6 \mathrm{ml}$ of chloroform. $25 \mathrm{ml}$ of $0.5 \mathrm{~L}$ alcoholic $\mathrm{KOH}$ under reflux condenser was heated for 30mins, the solution was then 
allowed to cool at room temperature and phenolphthalein was added. The resulting solution was titrated against $0.5 \mathrm{M} \mathrm{HCl}$, until the solution became colourless. The blank was also prepared with all the reagents in the sample.

Saponification value $=$ difference in titre value of the blank and the sample $* 0.5 \mathrm{M} * 1000$

$$
\text { weight of oil * } 56.1
$$

\subsubsection{Determination of Specific Gravity}

$10 \mathrm{ml}$ density bottle was filled with oil sample to the $10 \mathrm{ml}$ mark, the weight of the oil sample was determined on a weighing balance; equal volume of water was replaced for the oil in the density bottle and weighed, and recorded.

$$
\text { Specific gravity }=\frac{\text { weight of the oil sample }}{\text { weight of water sample }}
$$

\subsubsection{Determination of $\mathrm{pH}$ Value}

The $\mathrm{pH}$ meter was first calibrated with the standard buffers of 4 and 9, and then confirmed using distilled water of $\mathrm{pH} 7.0$, thereafter the $\mathrm{pH}$ of the oil sample was determined

\section{RESULTS AND ANALYSIS}

\subsection{Proximate Composition of Seeds}

The lipid content, moisture content and ash content were found to be low respectively. This indicates that the oil cannot serve as a moisturizer.

Table1. Values are mean \pm standard deviation of three determinations

\begin{tabular}{|l|c|}
\hline \multicolumn{2}{|c|}{ Proximate composition of seeds } \\
\hline Composition & \% content \\
\hline Lipid & $4.43 \pm 0.11$ \\
\hline Moisture & $20.5 \pm 5.65$ \\
\hline Ash & $4.35 \pm 0.43$ \\
\hline
\end{tabular}

\subsection{Physiochemical Composition of Oil}

From the results above, it was found that the acid value is high; this is an indication that the oil can undergo self hydrolytic reaction, which implies that it cannot be stored for a very long period of time. This however can be guided against by purifying the oil. The saponification value was also found to be high which indicate that a high amount of alkaline will be needed to neutralize a given amount of the oil. The specific gravity at 29.1 is low in relative to water, and this is typical of all oil. Its bulk density in large scale production can be relatively managed with ease. Thus, the impact on product indicates a close ratio equivalent of weight and volume in production estimations. $\mathrm{pH}$ value is low which may alter the physical properties of polymer if used as processing aids (oil); this is because, process oils can only do well when they are alkaline.

Table2. Values are mean \pm standard deviation of three determinations

\begin{tabular}{|l|c|}
\hline \multicolumn{2}{|c|}{ Physiochemical composition of oil } \\
\hline Parameters & Value \\
\hline Acid value & $39.27 \pm 4.26$ \\
\hline pH value at $25^{\circ} \mathrm{C}$ & $4.95 \pm 1.02$ \\
\hline Saponification value & $267.4 \pm 12.8$ \\
\hline Specific gravity at $29.1^{\circ} \mathrm{C}$ & $1.13 \pm 0.81$ \\
\hline
\end{tabular}

\section{Conclusion}

The above results reveal that the oil of Mucuna mucunoide cannot be used as process aids in rubber (polymer) industry, though its seeds are readily available. Moreover, the oil was observed to possess some pharmaceutical significance which makes it relevant for use in the field of medicine. 


\section{REFERENCES}

Amstrong, W.P. (2001). Waynesword. http: //waynesword.palomar.edu / wayne.htm.

Rich, E.C. and Teixera, A.A. (). Applied Engineering in Agriculture. Vol.21 = 3, 437 /443.

Haubenestel, K. esser, B. Gertzen and Pritsechins. (2007). U.S. Patent

Blow, C.M and Hepbrun, C. (1982). Rubber Technology and Manufacture. 2nd Ed., Butterworth London.

Horn, J.B. Materials for Compounding and Reinforcement. (1968). $3^{\text {rd }}$ Edition

Citation: F.E Omofuma, "Extraction and Characterization of Mucuna Seeds Oil", International Journal of Advanced Research in Chemical Science (IJARCS), vol. 4, no. 4, p. 31, 2017. http://dx.doi.org/ 10.20431/ 2349-0403.0404003

Copyright: (C) 2017 Authors. This is an open-access article distributed under the terms of the Creative Commons Attribution License, which permits unrestricted use, distribution, and reproduction in any medium, provided the original author and source are credited. 